\title{
Cephalometric Indicator of Obstructive Sleep Apnea in Relation to Severity and Sites of Obstruction in Non-Obese Male Patients
}

\author{
Osama A Alsaddik ${ }^{1, *}$, Fayez K Saleh ${ }^{2}$ and Sara N Aksamawati ${ }^{3}$ \\ ${ }^{1}$ Masters in Orthodontics, Beirut Arab University, Lebanon \\ ${ }^{2}$ Professor of orthodontics in faculty of dentistry, Beirut Arab University, Lebanon \\ ${ }^{3}$ Masters in Pediatric dentistry, Lebanese University, Lebanon
}

*Corresponding author: Osama A Alsaddik, Masters in Orthodontics, Beirut Arab University, Beirut, Lebanon, E-mail: osa954@hotmail.com

Received: 23 Jan, 2019 | Accepted: 19 Mar, 2019 | Published: 26 Mar, 2019

Citation: Alsaddik OA, Saleh FK, Aksamawati SN (2019) Cephalometric Indicator of Obstructive Sleep Apnea in Relation to Severity and Sites of Obstruction in Non-Obese Male Patients. Int J Dent Oral Health 5(2): dx.doi.org/10.16966/2378-7090.288

Copyright: (c) 2019 Alsaddik OA, et al. This is an open-access article distributed under the terms of the Creative Commons Attribution License, which permits unrestricted use, distribution, and reproduction in any medium, provided the original author and source are credited.

\begin{abstract}
Obstructive Sleep Apnea (OSA) is characterized by episodic cessation of breathing during sleep. Upper airway patency is determined by an interactive role of anatomic and neuromuscular factors. Craniofacial skeletal and upper airway soft tissue morphology, obesity, sleeps position represents a few of the determinant factors. Cephalometric characteristics for OSA patients include mandibular deficiency, bimaxillary retrusion, and reduced cranial base angle, decreased mandibular length and increased lower anterior facial height.
\end{abstract}

Treatment of OSA depends mainly on the severity and site of obstruction and is either surgical or non-invasive treatment.

Objective: The study evaluated the dentofacial characteristics of (OSA) patients in Lebanese non obese male population and compared them with normal group according to severity and sites of obstruction.

Materials and Methods: A total of 67 subjects were recruited for the study, 42 subjects were diagnosed with OSA by previous polysomnography tests at the American University in Beirut Medical Center Sleep Laboratory. 25 non-OSA subjects were recruited as controls. Based on Apnea-Hypopnea index $(\mathrm{AHI})$ value, the patients were divided into mild-to-moderate and severe group. Cephalometric measurements and physical examination of the tonsils were used to classify the OSA patients into groups according to sites of obstruction. Cephalometric X-rays were taken and digitized for linear and angular values.

Results: Regarding severity groups, no statistically significant differences were observed in age, BMI, or angular measurements between the three severity groups except for the angular measurement (C3-H-Me). However, for linear measurements; the soft palate length, the soft palate thickness, Jarabak facial ratio; the distance between the PNS and point V; and the distance between the hyoid and the following : tongue base, mandibular plane and C3-Me were found significant.

As for sites of obstruction, no statistically significant differences were observed in angular measurements between the three groups except for C3$\mathrm{H}-\mathrm{Me}$. However, the soft palate thickness, the distance between the PNS and point V; and the distance between the hyoid and the following: tongue base, mandibular plane and C3-Me were found significant.

Conclusion: This study revealed that certain Craniofacial and upper airway soft tissue characteristics exist in relation to severity of OSA and sites of obstruction. (C3-Me perpendicular to the hyoid bone) is a significant predictor of OSA in non-obese Lebanese male subjects.

Keywords: Sleep; Apnea; Lebanese; Cephalometric; Hyoid; Indicator; Obstructive; Non obese; Severity

\section{Introduction}

Obstructive Sleep Apnea syndrome (OSA) is characterized by episodic cessation of breathing during sleep. There is a controversy concerning the cause and effect of sleep apnea and certain abnormal craniofacial pattern. There are certain cephalometric characteristics for OSA patients in relation to severity and sites of obstruction and these include mandibular deficiency, bimaxillary retrusion, reduced cranial base angle, decreased mandibular length; increased lower anterior facial height, inferiorly positioned hyoid, and elongated Soft Palate as revealed by Koubayashi, et al. [1] and Hou, et al. [2]. Previous studies by Bacon, et al. [3]; Kubota, et al. [4]; Lowe, et al. [5]; and Lowe, et al. [6] investigated facial characteristics of OSA patients in relation to severity and sites of obstruction and found that certain dentofacial characters could be used as diagnostic measures and aid in treatment planning of those patients. Since no cephalometric studies have been 
conducted on obstructive sleep apnea on the Lebanese population and few studies have investigated the relationship between the dentofacial characteristics and obstructive sites in patients with OSA, this justified the conduct of the study since proper diagnosis is the key to understanding the etiology of OSA and the proper treatment plan.

\section{Materials and Methods}

A total of 67 subjects were recruited, 42 subjects were diagnosed with OSA by previous polysomnography test at the American University in Beirut Medical Center Sleep Laboratory. The polysomnography test was performed using overnight polysomnography including EEG (electroencephalography), ECG (electrocardiography), and EOG (electrooculography), sub mental EMG (electromyography), airflow, tracheal sound with microphone, arterial oxygen saturation $\left(\mathrm{SpO}_{2}\right)$, and respiratory effort. Additionally, 25 non-OSA control subjects were recruited from a pool of class I malocclusion patients from the Orthodontic Department at Beirut Arab University.

\section{Inclusion: (All subjects including control)}

- Lebanese males

- Age between 30 and 60 years

- Non-obese at the time of their recruitment: Body Mass Index $(\mathrm{BMI})<30$. BMI is calculated as $\left[\mathrm{BMI}=\right.$ weight $(\mathrm{kg}) \div$ height $\left.^{2}(\mathrm{~m})\right]$.

\section{Exclusion}

- Prior history of orthodontic treatment or craniofacial abnormality (applies for both OSA and non-OSA Subjects).

- Control patients with symptoms or features suggestive of OSA despite not doing PSG sleep study such as: snoring, nocturnal apnea, or excessive daytime sleepiness.

All participants signed a consent form after having an explanation on the subject, benefits, and minimal risk if any, when participating in our research study. Approval for the study was obtained from the ethics committee and IRB at the American University in Beirut Medical Center (AUBMC).

For every patient a lateral cephalometric X-ray was obtained in the Natural head position which is a standardized position of the head in an upright posture with the eyes focused on a point in the distance at eye level, which implies that the visual axis is horizontal. With the same machine and practitioner.

Every cephalometric X-ray was traced on acetate paper and then digitized by a scanner for landmark identification as shown in figure 1 and table 1; and measurement of linear and angular values, as shown in table 2, using the dentofacial Planner Program ${ }^{\circ}$ was done.

\section{Severity groups}

The subjects were categorized into three severity groups based on their polysomnography test results specifically their AHI values as advocated by the American Academy of Sleep Medicine 2007 which indicates the number of respiratory irregularities per sleep hour and is calculated with this formula: [(total number of apneas+hypopneas)/ (total sleep time in minutes) $] \div 60$. An AHI index value exceeding 5 indicates the presence of OSA.

In our research used the definition of Apnea as periods of no breathing while hypopnea means slow or shallow breathing in which the PSG reports the following:

i. The peak signal excursions drop by $\geq 30 \%$ of pre-event baseline using nasal pressure and PAP device flow. ii. The duration of the $\geq 30 \%$ drop in signal excursion is $\geq 10$ seconds.

iii. There is $\mathrm{a} \geq 3 \%$ oxygen desaturation from pre-event baseline and/or the event is associated with an arousal.

\section{The groups were as follow:}

- Control or non-OSA subjects: $\mathrm{AHI}<5$

- Mild to moderate OSA: $5 \leq \mathrm{AHI}<30$

- Severe OSA: AHI $\geq 30$

\section{Obstructive site groups}

We used the narrowest portion of the airway in the cephalometric radiograph taken in the awake upright subjects and physical examination of the tonsils to classify the OSA patients into groups according to sites of obstruction for further dentofacial characteristics description which may be one of the following as shown by Baik, et al. [7] and illustrated in figure 2:

1) Obstruction at the Retropalatal and Retroglossal region (Rp plus Rg group) in which the linear cephalometric values for Rp is calculated as the distance from Point (Sbtn) to Point (Phwn), and $\mathrm{Rg}$ as the distance from Point (U) to Point (ppw2), those two linear cephalometric values were used to classify the obstruction site groups if they both were less or equal to $6 \mathrm{~mm}$,

2) Obstruction at the Retropalatal region (Rp group) in which the linear cephalometric value for Rp (Sbtn-Phwn) is less or equal to $6 \mathrm{~mm}$, as shown in figure 2 .

3) Obstruction due to tonsillar hypertrophy (tonsillar hypertrophy group). Classification in this group had 2 criteria. Patients were assigned to the tonsillar hypertrophy group when the appearance of their tonsils was Mackenzie's Class II or III (I: tonsils just visible beyond the palatal arch; II: intermediate enlargement; III: tonsils appearing to contact each other at the midline) as cited from Fukuda, et al. [8]; and when the values of cephalometric linear measurement (Sbtn-phwn) or (U-ppw2) exceeded $6 \mathrm{~mm}$ on cephalometric X-ray.

The site of obstruction was further confirmed by the full night measurement of the oropharyngeal and esophageal pressure that we found in the patient's records since polysomnography will not be repeated for the purposes of this research.

\section{Demographic and sleep data}

Demographic and sleep data are summarized in table 3 . The mean age and BMI of the control group were 31.4 years and $25.8 \mathrm{~kg} / \mathrm{m}^{2}$; the mild to moderate OSA group, 42.8 years and $26.1 \mathrm{~kg} / \mathrm{m}^{2}$ with mean AHI of $18 \pm 6.9$; and the severe OSA group, 41.8 years and $26.6 \mathrm{~kg} / \mathrm{m}^{2}$ with mean $\mathrm{AHI}$ of $40.6 \pm 5.3$ respectively.

Matching: OSA patients will be ( \pm 10 years) matched to the age of non OSA subjects. The relatively wide range in age matches is meant to allow for the single 25 subject non-OSA group to serve as an age match to the 2 OSA severity groups.

\section{Additional Considerations at recruitment:}

- $\quad$ Uniform sampling of the AHI range for each group were attempted to ensure that there is an even distribution of AHI values. This is needed for: (1) Quantitative correlation of Cephalometric data and OSA severity and (2) Multivariate modeling of AHI scores (MLR).

- Upon approaching these subjects, information about their current weight were collected to exclude the possibility of having a substantially altered BMI score from the previously conducted PSG study. 




Figure 1: Angular and Linear measurements used in this study.

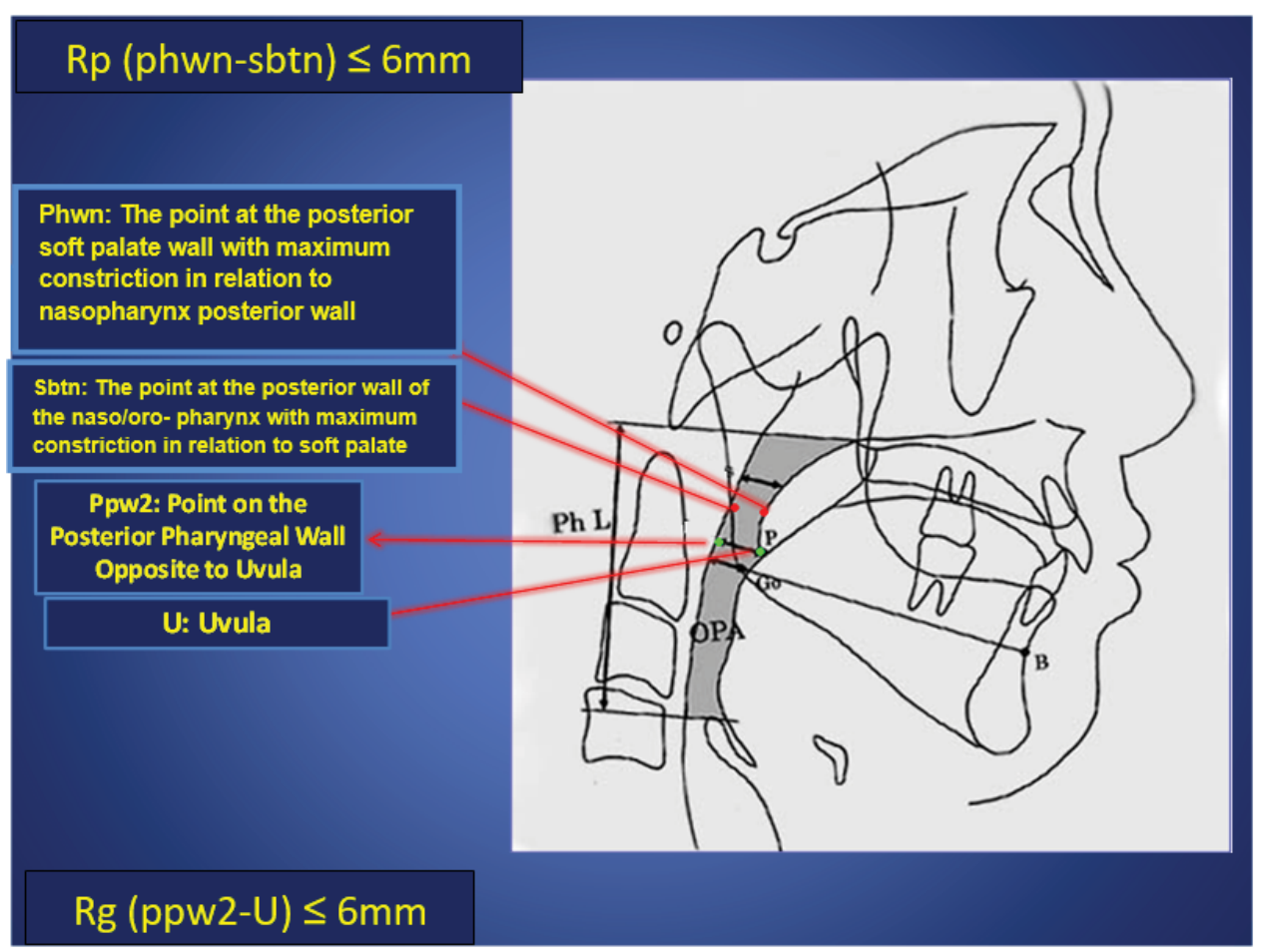

Figure 2: Retro-palatal and Retro-glossal Sites of Naso-pharyngeal and Oro-pharyngeal Obstruction. 


\section{Sample size calculation}

Since there is no available data on the prevalence of dentofacial defects among OSA patients, or even data on the dentofacial characteristics of Lebanese OSA patients, a quick literature review was done to estimate the variation of means of the different Cephalometric measurements among the three different groups - as classified according to AHI scores. According to Chang and Shiao (2008), measurement of the distance of anterior superior hyoid to mandibular plane $(\mathrm{MPH})$ among the four different groups was the following:

\begin{tabular}{|c|c|c|c|c|}
\hline $\begin{array}{c}\text { MPH } \\
\text { means }\end{array}$ & $\mathrm{AHI}<5$ & $\begin{array}{c}5 \leq \\
\mathrm{AHI}<15 \text { (mild) }\end{array}$ & $\begin{array}{c}15 \leq \\
\mathrm{AHI}<30 \text { (moderate) }\end{array}$ & $\begin{array}{c}\mathrm{AHI} \geq \\
30(\text { severe })\end{array}$ \\
\cline { 2 - 6 }$( \pm \mathrm{SD})$ & $18.9( \pm 9.8)$ & $15.3( \pm 5.9)$ & $17.4( \pm 4.5)$ & $24.7( \pm 11.5)$ \\
\hline
\end{tabular}

Based on the above difference in MPH means, an average in the mean difference in MPH of approximately 8.0 was taken with a standard deviation of 7.5 to calculate the sample size needed for comparison of the three different groups (ANOVA). Having a study

Table 1: Landmarks Definition.

\begin{tabular}{|c|c|}
\hline Anterior Nasal Spine (ANS) & The anterior tip of the nasal spine at the lower margin of the anterior nasal opening. \\
\hline Articulare (Ar) & $\begin{array}{l}\text { The point of intersection of the posterior border of the condyle and the inferior border of the basilar part of the } \\
\text { occipital bone. }\end{array}$ \\
\hline Condylion (Cd) & $\begin{array}{l}\text { The most superior point on the curvature of the condylar head. It is located as the most superior axial point of the } \\
\text { condylar head rather than as the most superior point on the condyle. }\end{array}$ \\
\hline C3 & The most anterioinferior point on the curvature of the third vertebrae \\
\hline Gnathion (Gn) & $\begin{array}{l}\text { The most anterioinferior point on the contour of the bony chin symphysis. It is constructed by intersecting a line drawn } \\
\text { perpendicular to the line connecting PG and ME. }\end{array}$ \\
\hline Gonion (Go) & The constructed point where the ramus plane and the mandibular plane intersect \\
\hline Hyoid $(\mathrm{H})$ & The most superoanterior point on the body of the Hyoid bone. \\
\hline Lower Incisor Apex & The root tip of the most anterior mandibular central incisor. \\
\hline Lower Incisor Incisal Edge & The Incisal tip of the mandibular central incisor. \\
\hline Menton (Me) & The most inferior point on the Symphysal outline of the mandible. \\
\hline Nasion (N) & The most anterior point of the Nasofrontal suture or the most posterior point on the curve at the bridge of the nose. \\
\hline Orbitale (Or) & The lowest point on the external border of the orbital cavity, tangent to the Frankfort plane. \\
\hline Pogonion (Pg) & The most anterior point on the Symphysis. It is determined by a tangent through $\mathrm{N}$. \\
\hline Point A & The most posterior point on the labial surface of the maxilla between the anterior nasal spine and the dental alveolus. \\
\hline Point B & $\begin{array}{l}\text { The most posterior point from a line drawn from ID to PG on the anterior surface of the Symphyseal outline of the } \\
\text { mandible. }\end{array}$ \\
\hline Porion (Pr) & The most superior point of the external auditory meatus, tangent to the Frankfort plane. \\
\hline PNS & The most posterior point at the sagittal plane on the dorsal surface of the maxilla. \\
\hline $\begin{array}{l}\text { Premolar Mesial Contact } \\
\text { Point(PCT) }\end{array}$ & $\begin{array}{l}\text { Established by the intersection of a line along the occlusal contact of the upper and lower premolars and a perpendicular } \\
\text { line to it through the averaged anterior contact of the first maxillary premolars with the maxillary cuspid. }\end{array}$ \\
\hline Sella Turcica & A constructed point representing the center of the pituitary fossa. \\
\hline Upper Incisor Apex & The root tip of the maxillary central incisor. \\
\hline Upper Incisor Incisal Edge & The Incisal tip of the maxillary central incisor \\
\hline $\begin{array}{l}\text { Upper Molar Mesial Cusp } \\
\text { Tip(MCT) }\end{array}$ & The anterior cusp tip of the maxillary first molar. \\
\hline Sbtn & The point at the posterior soft palate wall with maximum constriction in relation to Nasopharynx posterior wall \\
\hline Phwn & The point at the posterior wall of the Naso/oro-Pharynx with maximum constriction in relation to soft palate \\
\hline TB & Tongue Tip \\
\hline SPC & The anterior point of the soft palate that has maximum convexity. \\
\hline SPD & The posterior point of the soft palate that has maximum convexity in relation to Nasopharynx \\
\hline Ppw2 & Point on posterior pharyngeal wall opposite to the Uvula \\
\hline $\mathrm{U}$ & The tip of the Uvula \\
\hline $\mathrm{V}$ & Valeculla, the most posterioinferior base of the tongue \\
\hline Mandibular plane & The plane from Point Go to Point Me \\
\hline Frankfort Horizontal & The plane from point Orbitale to Point Porion \\
\hline
\end{tabular}


Table 2: Linear and angular Measurements definition.

\begin{tabular}{|c|c|}
\hline Y-axis to SN & The angle between planes S-Me and S-N \\
\hline Gonial angle & The angle between Point Go and Points Ar and Me \\
\hline FMIA & Frankfort Mandibular Incisal Angle: the angle between Frankfort plane and mandibular incisal plane \\
\hline Soft palate angulation & The angle between Point PNS and Points ANS and $U$ \\
\hline $\mathrm{C} 3-\mathrm{H}-\mathrm{Me}$ & The angle between Point $\mathrm{H}$ to Points $\mathrm{C} 3$ and $\mathrm{Me}$ \\
\hline Go - Gn & The distance from Point Gonion to Point Gnathion that measure mandibular length \\
\hline ANS-Me(ALFH) / N-Me(ATFH) & The ratio between anterior lower facial height and anterior total facial height \\
\hline PNS-U & The distance between Point Posterior nasal spine and Uvula \\
\hline PNS-V & The distance between Point Posterior nasal spine and Valeculla \\
\hline $\mathrm{H}-\mathrm{TB}$ & The distance between hyoid bone and tip of the tongue \\
\hline Sbtn-Phwn & The maximum constriction in the Nasopharynx \\
\hline soft palate thickness & The distance between point SPC and point SPD \\
\hline S-Go/N-Me \% & Jarabak facial ratio: Ratio between points $\mathrm{S}$ and $\mathrm{Go}$ to $\mathrm{N}$ and $\mathrm{Me}$ \\
\hline H perp. MP & The distance between a perpendicular from Point hyoid and mandibular plane \\
\hline H perp. C3-Me & The distance between a perpendicular from Point hyoid and constructed plane from point C3 to Menton \\
\hline
\end{tabular}

Table 3: Demographic and sleep data.

\begin{tabular}{|l|l|l|l|}
\hline \multicolumn{1}{|c|}{ Age } & \multicolumn{1}{c|}{ BMI mean } & \multicolumn{1}{c|}{ AHI, No./h } \\
\hline Control & $31.48 \pm 6.17$ & $25.88 \pm 0.79$ & \\
\hline Mild to Moderate OSA & $42.85 \pm 8.57$ & $26.17 \pm 1.3$ & $18 \pm 6.91$ \\
\hline Severe OSA & $41.86 \pm 9.3$ & $26.65 \pm 1.16$ & $40.68 \pm 5.31$ \\
\hline
\end{tabular}

power of $80 \%$ and type I error of $5 \%$, we calculated a sample size of 20 subjects per group. (Analysis done by the Biostatistics Unit at the American University in Beirut-CRI).

The mild and moderate groups consisted of 20 subjects and, were therefore added together in one group with $\mathrm{AHI}$ range: $(5 \leq \mathrm{AHI}<30)$; while the severe group consisted 22 subjects with $\mathrm{AHI}$ range: (AHI $\geq$ $30)$.

\section{Statistical methods for data analysis}

Analysis was performed using the SPSS version 18.0 (IBM Corporation, Illinois, Chicago, USA) statistical package for Windows ${ }^{\bullet}$. Data was tested for normal distribution using the Shapiro Wilk, and Lielliefors tests; and Levene's test for testing homogeneity of variances. Continuous variables will be expressed as mean \pm standard deviation. Categorical variables were reported as frequencies and percentages. Standard descriptive statistics were determined. Univariate Analysis was conducted as appropriate using Fisher Exact test for categorical variables; and Welch's Robust and Kruskal Wallis tests for continuous variables. One way Analysis of Variance (ANOVA) test was used to evaluate the association between the different individual cephalometric measurements and OSA presence or severity (3 groups). Correlations between AHI scores and the cephalometric measurements (continuous) were also assessed (Pearson correlation).

Multivariate analyses were done as follows:

1-General Linear Model GLM: ANOVA with AHI score as dependent variable and each cephalometric measure as the independent variable.

2-Multiple linear regression analysis (MLR): MLR was also performed using backward elimination method to determine the cephalometric and other predictor variables that explain variations in AHI values in the Lebanese male population considering demographics. The model results were confirmed using the Forward
Selection and Stepwise Regression Methods. A p-value $<0.2$ was used for initial inclusion in the multivariate modeling, and $\mathrm{p} \leq 0.05$ was used for retaining variables in the final multivariate regression model. A p-value $\leq 0.05$ (two sided) was used to indicate significance in all cases.

\section{Results}

\section{Severity results}

The significant variables found from normality testing as shown in table 4, were tested by: Fisher's ANOVA test; Welch's robust test; and Kruskal-Wallis test and no statistically significant differences were observed in angular measurements between the three groups except for the angular measurement (C3-H-Me). However, for linear measurements; the soft palate length, the soft palate thickness, Jarabak facial ratio; the distance between the PNS and point V; and the distance between the hyoid and the following: Tongue base, mandibular plane and C3-Me differences were found significant. For the eight variables that we found significant, we did not have equality in significances between the three severity groups, hence; those variables were compared two by two for further understanding of differences between the groups according to severity as shown in table 5 .

Multiple linear regression analysis was done for AHI and the following variables: $\mathrm{H}$ perpendicular MP; soft palate angulation, PNS-U, H perpendicular C3-Me and Jarabak Facial Ratio. Only $\mathrm{H}$ perpendicular MP $\left(\mathrm{R}_{2}=0.278, \mathrm{P}<0.05\right)$ and $\mathrm{H}$ perpendicular $\mathrm{C} 3-\mathrm{Me}$ $\left(\mathrm{R}_{2}=0.508, \mathrm{P}<0.05\right)$ were significant. $\mathrm{H}$ perpendicular $\mathrm{C} 3-\mathrm{Me}$ showed the highest regression as shown in table 6 so it was tested for the appropriate model and showed a cubic figure in relation to AHI as shown in figure 3 .

The findings of this study have shown that the position of the hyoid bone in mild to moderate OSA patients was below but near the straight line from the $\mathrm{C} 3$ to $\mathrm{Me}$ (mean: $7.5 \mathrm{~mm} \pm 2.4$ ), whereas the position of the hyoid bone in severe OSA patients was far below this line (mean: $15.7 \mathrm{~mm} \pm 4.7)$. This was in agreement to the findings of Sakakibara, et al. [9]; Tsai, et al. [10]; and Kurt, et al. [11].

The results showed a low hyoid bone position in conjunction with a constricted posterior upper airway space (Sbtn-Phwn) in both severity groups (mild to moderate mean: $6.2 \mathrm{~mm} \pm 2$; severe mean: $5.7 \mathrm{~mm} \pm$ 
Table 4: Tests of normality for the angular and linear measurements between the control, mild-moderate and severe groups. Level of significance: $\mathrm{P}<0.05$.

\begin{tabular}{|c|c|c|c|c|c|}
\hline Variable & Group & Lilliefors Sig. & Judgment at $5 \%$ : Normality is & Shapiro-Wilk sign. & Judgment at $\mathbf{5 \%}$ : Normality is \\
\hline \multirow{3}{*}{ Y-axis to SN } & Control & 0.135 & not rejected & 0.582 & not rejected \\
\hline & Mild & 0.2 & not rejected & 0.286 & not rejected \\
\hline & Severe & 0.2 & not rejected & 0.837 & not rejected \\
\hline \multirow{3}{*}{ Gonial angle } & Control & 0.057 & not rejected & 0.402 & not rejected \\
\hline & Mild & 0.048 & rejected & 0.044 & rejected \\
\hline & Severe & 0.2 & not rejected & 0.347 & not rejected \\
\hline \multirow{3}{*}{ FMIA } & Control & 0.2 & not rejected & 0.424 & not rejected \\
\hline & Mild & 0.2 & not rejected & 0.441 & not rejected \\
\hline & Severe & 0.111 & not rejected & 0.262 & not rejected \\
\hline \multirow{3}{*}{ Soft palate angulation } & Control & 0.109 & not rejected & 0.148 & not rejected \\
\hline & Mild & 0.2 & not rejected & 0.471 & not rejected \\
\hline & Severe & 0.174 & not rejected & 0.461 & not rejected \\
\hline \multirow{3}{*}{ C3-H-Me } & Control & 0.2 & not rejected & 0.14 & not rejected \\
\hline & Mild & 0.2 & not rejected & 0.899 & not rejected \\
\hline & Severe & 0.026 & rejected & 0.072 & not rejected \\
\hline \multirow{3}{*}{ Go - Pg } & Control & 0.168 & not rejected & 0.263 & not rejected \\
\hline & Mild & 0 & rejected & 0 & rejected \\
\hline & Severe & 0.2 & not rejected & 0.891 & not rejected \\
\hline \multirow{3}{*}{$\begin{array}{l}\text { ANS-Me(ALFH) } \\
\text { /N-Me(ATFH) }\end{array}$} & Control & 0.2 & not rejected & 0.362 & not rejected \\
\hline & Mild & 0.2 & not rejected & 0.397 & not rejected \\
\hline & Severe & 0.032 & rejected & 0.154 & not rejected \\
\hline \multirow{3}{*}{ PNS-U } & Control & 0.2 & not rejected & 0.252 & not rejected \\
\hline & Mild & 0.2 & not rejected & 0.544 & not rejected \\
\hline & Severe & 0.2 & not rejected & 0.135 & not rejected \\
\hline \multirow{3}{*}{ PNS-V } & Control & 0.2 & not rejected & 0.559 & not rejected \\
\hline & Mild & 0.2 & not rejected & 0.786 & not rejected \\
\hline & Severe & 0.2 & not rejected & 0.512 & not rejected \\
\hline \multirow{3}{*}{$\mathrm{H}-\mathrm{TB}$} & Control & 0.2 & not rejected & 0.337 & not rejected \\
\hline & Mild & 0 & rejected & 0 & rejected \\
\hline & Severe & 0.088 & not rejected & 0.209 & not rejected \\
\hline \multirow{3}{*}{ Sbtn-Phwn } & Control & 0.042 & rejected & 0.001 & rejected \\
\hline & Mild & 0 & rejected & 0.001 & rejected \\
\hline & Severe & 0.006 & rejected & 0.003 & rejected \\
\hline \multirow{3}{*}{ soft palate thickness } & Control & 0.2 & not rejected & 0.257 & not rejected \\
\hline & Mild & 0.114 & not rejected & 0.333 & not rejected \\
\hline & Severe & 0.087 & not rejected & 0.001 & rejected \\
\hline \multirow{3}{*}{ S-Go/N-Me \% \#321 } & Control & 0.195 & not rejected & 0.464 & not rejected \\
\hline & Mild & 0.2 & not rejected & 0.875 & not rejected \\
\hline & Severe & 0.2 & not rejected & 0.918 & not rejected \\
\hline \multirow{3}{*}{ H perp. MP } & Control & 0.2 & not rejected & 1 & not rejected \\
\hline & Mild & 0.2 & not rejected & 0.913 & not rejected \\
\hline & Severe & 0.2 & not rejected & 0.661 & not rejected \\
\hline \multirow{3}{*}{ H perp. C3-Me } & Control & 0.2 & not rejected & 0.105 & not rejected \\
\hline & Mild & 0.2 & not rejected & 0.394 & not rejected \\
\hline & Severe & 0.005 & rejected & 0.001 & rejected \\
\hline
\end{tabular}


Table 5: ANOVA tests for angular and linear measurements in severity groups. Level of significance at $P<0.05$.

\begin{tabular}{|c|c|c|c|c|c|}
\hline \multirow{2}{*}{$\begin{array}{l}\text { ANOVA by groups (Control, } \\
\text { Mild, and severe) }\end{array}$} & \multirow{2}{*}{$\begin{array}{c}\begin{array}{c}\text { Levene's Test for } \\
\text { homogeneity of variances }\end{array} \\
\text { Sig. }\end{array}$} & \multicolumn{2}{|c|}{ Fisher's ANOVA Test } & \multirow{2}{*}{$\begin{array}{c}\text { Welch's robust Test } \\
\text { Sig. }\end{array}$} & \multirow{2}{*}{$\begin{array}{c}\text { Kruskal-Wallis Test } \\
\text { Sig. }\end{array}$} \\
\hline & & R-square & Sig. & & \\
\hline Y-axis to SN & 0.972 & 0.045 & 0.231 & 0.224 & 0.282 \\
\hline Gonial angle & 0.173 & 0.001 & 0.972 & 0.962 & 0.877 \\
\hline FMIA & 0.565 & 0.007 & 0.789 & 0.8 & 0.772 \\
\hline Soft palate angulation & 0.19 & 0.007 & 0.795 & 0.777 & 0.818 \\
\hline C3-H-Me & 0.037 & 0.379 & 0 & 0 & 0 \\
\hline Go-Pg & 0.513 & 0.086 & 0.055 & 0.147 & 0.174 \\
\hline ANS-Me(ALFH)/N-Me(ATFH) & 0.118 & 0.041 & 0.266 & 0.293 & 0.308 \\
\hline PNS-U & 0.203 & 0.119 & 0.017 & 0.006 & 0.012 \\
\hline PNS-V & 0.488 & 0.4 & 0 & 0 & 0 \\
\hline H-TB & 0.146 & 0.387 & 0 & 0 & 0 \\
\hline Sbtn-Phwn & 0.672 & 0.043 & 0.242 & 0.285 & 0.08 \\
\hline Soft palate thickness & 0.072 & 0.244 & 0 & 0 & 0 \\
\hline S-Go/N-Me \% \#321 & 0 & 0.98 & 0 & 0 & 0 \\
\hline H perp. MP & 0.007 & 0.569 & 0 & 0 & 0 \\
\hline H perp. C3-Me & 0.007 & 0.536 & 0 & 0 & 0 \\
\hline
\end{tabular}

Table 6: Multiple comparisons between significant measurements and severity groups. Level of significance at $\mathrm{P}<0.05$.

\begin{tabular}{|c|c|c|c|c|c|}
\hline \multicolumn{6}{|c|}{ Multiple Comparisons } \\
\hline \multirow{2}{*}{ Variable } & \multirow{2}{*}{ Difference } & \multirow{2}{*}{ Mean Difference } & \multirow{2}{*}{ Sig. } & \multicolumn{2}{|c|}{ 95\% Confidence Interval } \\
\hline & & & & Lower Bound & Upper Bound \\
\hline \multirow{3}{*}{$\mathrm{C} 3-\mathrm{H}-\mathrm{Me}$} & Control - Mild & 1.684 & 0.89 & -7.088 & 10.456 \\
\hline & Control - Severe & 20.518 & 0 & 11.97 & 29.066 \\
\hline & Mild - Severe & 18.834 & 0 & 9.799 & 27.868 \\
\hline \multirow{3}{*}{ PNS-U } & Control - Mild & -2.494 & 0.318 & -6.597 & 1.609 \\
\hline & Control - Severe & -4.892 & 0.013 & -8.891 & -0.894 \\
\hline & Mild - Severe & -2.398 & 0.367 & -6.624 & 1.828 \\
\hline \multirow{3}{*}{ PNS-V } & Control - Mild & -6.953 & 0.01 & -12.496 & -1.41 \\
\hline & Control - Severe & -14.697 & 0 & -20.099 & -9.295 \\
\hline & Mild - Severe & -7.744 & 0.005 & -13.453 & -2.035 \\
\hline \multirow{3}{*}{ H-TB } & Control - Mild & -8.121 & 0.004 & -13.943 & -2.299 \\
\hline & Control - Severe & -14.991 & 0 & -20.664 & -9.319 \\
\hline & Mild - Severe & -6.87 & 0.021 & -12.866 & -0.875 \\
\hline \multirow{3}{*}{ Soft palate thickness } & Control - Mild & -2.291 & 0.004 & -3.939 & -0.643 \\
\hline & Control - Severe & -2.861 & 0 & -4.468 & -1.255 \\
\hline & Mild - Severe & -0.57 & 0.701 & -2.268 & 1.127 \\
\hline \multirow{3}{*}{ S-Go/N-Me \% \#321 } & Control - Mild & -65.402 & 0 & -68.773 & -62.031 \\
\hline & Control - Severe & -66.75 & 0 & -70.035 & -63.466 \\
\hline & Mild - Severe & -1.349 & 0.622 & -4.82 & 2.123 \\
\hline \multirow{3}{*}{ H perp. MP } & Control - Mild & -4.91 & 0.004 & -8.407 & -1.413 \\
\hline & Control - Severe & -12.988 & 0 & -16.396 & -9.58 \\
\hline & Mild - Severe & -8.078 & 0 & -11.68 & -4.476 \\
\hline \multirow{3}{*}{ H perp. C3-Me } & Control - Mild & -1.229 & 0.568 & -4.126 & 1.668 \\
\hline & Control - Severe & -9.489 & 0 & -12.312 & -6.667 \\
\hline & Mild - Severe & -9.489 & 0 & -11.244 & -5.277 \\
\hline
\end{tabular}


AHI

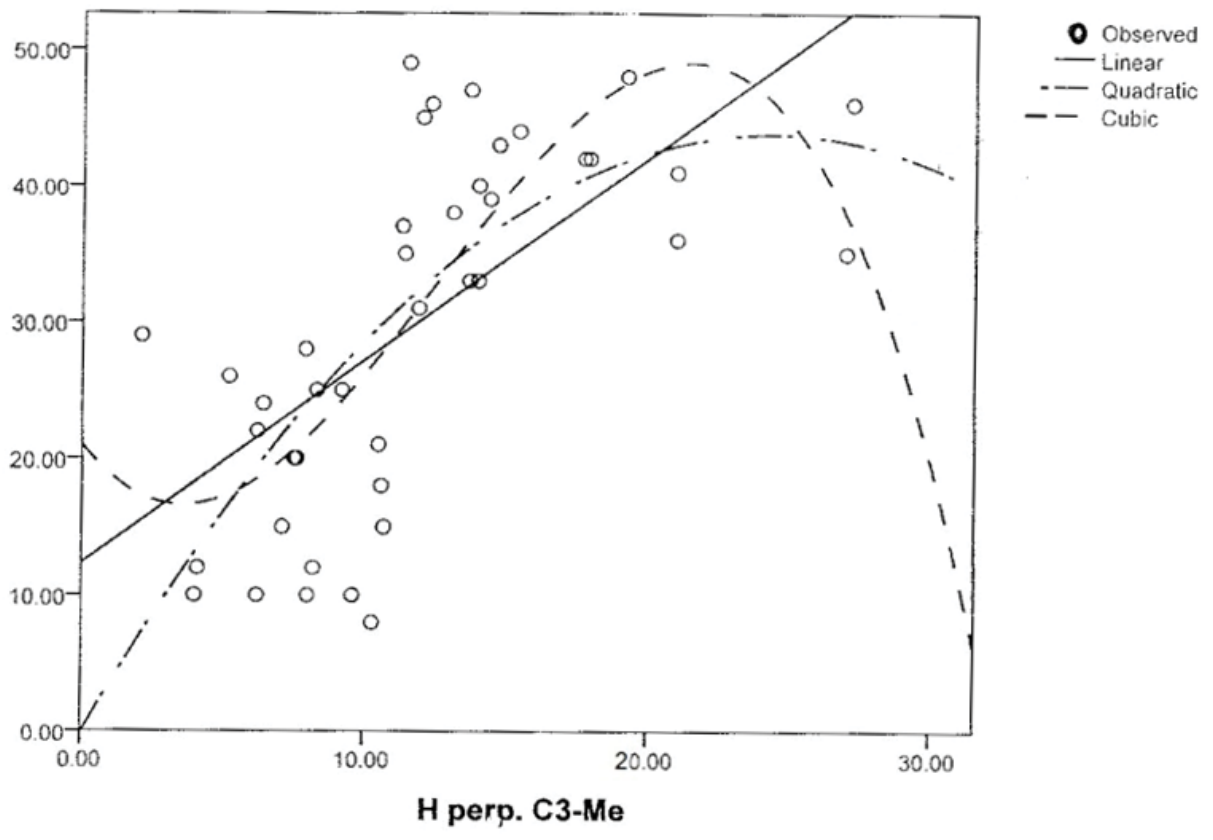

Figure 3: OSA severity predictive measurement ( $\mathrm{H}$ perpendicular $\mathrm{C} 3-\mathrm{Me}$ ) was tested for the appropriate model and showed a cubic figure in relation to $\mathrm{AHI}$.

2.3 ) in comparison to controls (mean: $6.9 \mathrm{~mm} \pm 2.5$ ) which was similar to the findings of Kurt, et al. [11].

The angle (C3-H-Me) was significantly decreased with severity compared to controls and that strengthens the relation of OSA severity and position of the hyoid bone (mild to moderate mean: $158.5 \mathrm{deg}$. \pm 8.5 ; severe mean: 139.7 deg. \pm 11.8 ). This was in agreement with Jamieson, et al. [12] and Tsai, et al. [13].

The results of this study have shown significant increase in soft palate length between the mild-to-moderate group (mean: $38.7 \mathrm{~mm}$ \pm 7.4 ), severe group $(41.1 \mathrm{~mm} \pm 4.8)$ and controls (mean: $36.2 \mathrm{~mm}$ \pm 4.8 ). A strong relation was found between OSA severity and soft palate length. Since there is tendency for the tone of the lingual and pharyngeal musculature to decrease during sleep and for the tongue and soft palate to fall backward in the supine position; therefore, we hypothesize that elongation of the soft palate in our study probably may have resulted from long-term vibration of the soft tissue by recurrent obstruction of the upper pharyngeal airway during sleep similar to the findings of Lyberg, et al. [14] and Hou, et al. [15].

The present findings revealed that the two OSA severity groups tongue base (PNS-V) was in a more inferior position in relation to control subjects (control mean: $68.9 \mathrm{~mm} \pm 7.3$; mild to moderate: $75.9 \mathrm{~mm} \pm 7.1$; severe mean: $83.6 \mathrm{~mm} \pm 8.6$ ). The tongue mass $(\mathrm{H}-\mathrm{TB})$ was significantly increased with severity when compared to controls. (control mean: $62.7 \mathrm{~mm} \pm 6.3$; mild to moderate mean: $70.8 \mathrm{~mm} \pm$ 70.8 ; severe mean: $77.7 \mathrm{~mm} \pm 9.2$ ), this means that in the two severity groups, more soft palate and tongue masses would occupy the upper airway space, and this in turn could make the upper airway more prone to obstruction as was shown by Lyberg, et al. [14] and Tsai, et al. [10]. In the supine position, the tongue falls back posteriorly due to gravity and obstructs the oropharyngeal space. This posterior encroachment by the tongue is counteracted only by the tone of the Genioglossal muscle. Thus, the thicker the tongue is, the more likely obstruction of the airway will occur during sleep.

The results of this study have also showed that the palate thickness was significantly higher with the severity of OSA in the mild to moderate group (mean: $12.1 \mathrm{~mm} \pm 2.7$ ) and severe group (mean: $12.6 \mathrm{~mm} \pm 2.7$ ) in comparison to control group (mean: $9.8 \mathrm{~mm} \pm 1.4$ ) but showed no significant difference between the mild to moderate and severe group indicating the role of soft palate thickness in collapse of the upper airway, which was in agreement with the findings of Tangugsorn, et al. [16] and Kurt, et al. [11].

As for the facial pattern, we used the Jarabak Facial Ratio (the percentage of the anterior and posterior facial proportions) which is obtained by the formula posterior facial height/anterior facial height $\times 100$. Anterior facial height is measured from Nasion to Menton and the posterior facial height is measured from Sella to Gonion. Values between $62-65 \%$ indicate a well balanced face, a higher percentage is seen in hypo divergent cases (short faces), whereas lower percentage is suggestive of hyper divergent cases (Long faces).

We found a hyper divergent facial type (excessive vertical development of the posterior facial height) for the two severity groups in comparison to controls (we found decreased Jarabak facial ratio (S-Go/N-Me\%): controls mean: $70 \pm 0$; mild to moderate mean: $66.1 \pm 5.7$; severe mean: $67.4 \pm 6.1$ ) which was in accordance with the findings of Tsai, et al. [13] in which greater lower anterior facial height was related to an overall increase in OSA severity in men; and severity of the OSA was related to the lower anterior portion in men (inferiorly positioned chin and hyoid bone) in which a larger Y-axis implies more downward mandibular growth and is related to greater lower facial height. This was further investigated by Hou, et al. [15] that documented several alterations in the craniofacial structure of 121 male patients with OSA, including posteriorly positioned maxilla and 
Table 7: Tests of Normality by sites of obstruction. $P$ value of significance: $P<0.05$.

\begin{tabular}{|c|c|c|c|c|c|}
\hline Variable & Group & Lilliefors Sig. & Judgment at 5\%: Normality is & Shapiro-Wilk sig. & $\begin{array}{c}\text { Judgment at } 5 \% \text { : } \\
\text { Normality is }\end{array}$ \\
\hline \multirow{3}{*}{ Y-axis to SN } & $R P+R g$ & 0.2 & not rejected & 0.751 & not rejected \\
\hline & Rt & 0.2 & not rejected & 0.999 & not rejected \\
\hline & $\mathrm{RP}$ & 0.2 & not rejected & 0.347 & not rejected \\
\hline \multirow{3}{*}{ Gonial angle } & $\mathrm{RP}+\mathrm{Rg}$ & 0.107 & not rejected & 0.065 & not rejected \\
\hline & Rt & 0.2 & not rejected & 0.579 & not rejected \\
\hline & $\mathrm{RP}$ & 0.2 & not rejected & 0.587 & not rejected \\
\hline \multirow{3}{*}{ FMIA } & $\mathrm{RP}+\mathrm{Rg}$ & 0.029 & rejected & 0.073 & not rejected \\
\hline & Rt & 0.2 & not rejected & 0.662 & not rejected \\
\hline & $\mathrm{RP}$ & 0.2 & not rejected & 0.482 & not rejected \\
\hline \multirow{3}{*}{ Soft palate angulation } & $\mathrm{RP}+\mathrm{Rg}$ & 0.176 & not rejected & 0.314 & not rejected \\
\hline & Rt & 0.2 & not rejected & 0.999 & not rejected \\
\hline & $\mathrm{RP}$ & 0.2 & not rejected & 0.162 & not rejected \\
\hline \multirow{3}{*}{ C3-H-Me } & $\mathrm{RP}+\mathrm{Rg}$ & 0.2 & not rejected & 0.639 & not rejected \\
\hline & Rt & 0.2 & not rejected & 0.587 & not rejected \\
\hline & $\mathrm{RP}$ & 0.2 & not rejected & 0.83 & not rejected \\
\hline \multirow{3}{*}{ Go - Pg } & $\mathrm{RP}+\mathrm{Rg}$ & 0.2 & not rejected & 0.152 & not rejected \\
\hline & Rt & 0.006 & rejected & 0 & Rejected \\
\hline & $\mathrm{RP}$ & 0.2 & not rejected & 0.043 & Rejected \\
\hline \multirow{3}{*}{ ANS-Me(ALFH)/N-Me(ATFH) } & $\mathrm{RP}+\mathrm{Rg}$ & 0.108 & not rejected & 0.181 & not rejected \\
\hline & Rt & 0.2 & not rejected & 0.264 & not rejected \\
\hline & $\mathrm{RP}$ & 0.2 & not rejected & 0.603 & not rejected \\
\hline \multirow{3}{*}{ PNS-U } & $\mathrm{RP}+\mathrm{Rg}$ & 0.2 & not rejected & 0.719 & not rejected \\
\hline & Rt & 0.2 & not rejected & 0.998 & not rejected \\
\hline & $\mathrm{RP}$ & 0.2 & not rejected & 0.297 & not rejected \\
\hline \multirow{3}{*}{ PNS-V } & $\mathrm{RP}+\mathrm{Rg}$ & 0.2 & not rejected & 0.823 & not rejected \\
\hline & Rt & 0.162 & not rejected & 0.11 & not rejected \\
\hline & $\mathrm{RP}$ & 0.2 & not rejected & 0.656 & not rejected \\
\hline \multirow{3}{*}{ H-TB } & $\mathrm{RP}+\mathrm{Rg}$ & 0.2 & not rejected & 0.455 & not rejected \\
\hline & Rt & 0.111 & not rejected & 0.126 & not rejected \\
\hline & $\mathrm{RP}$ & 0.058 & not rejected & 0.021 & Rejected \\
\hline \multirow{3}{*}{ Sbtn-Phwn } & $\mathrm{RP}+\mathrm{Rg}$ & 0.2 & not rejected & 0.296 & not rejected \\
\hline & Rt & 0 & rejected & 0 & Rejected \\
\hline & $\mathrm{RP}$ & 0.2 & not rejected & 0.514 & not rejected \\
\hline \multirow{3}{*}{ soft palate thickness } & $\mathrm{RP}+\mathrm{Rg}$ & 0.2 & not rejected & 0.248 & not rejected \\
\hline & Rt & 0.151 & not rejected & 0.103 & not rejected \\
\hline & $\mathrm{RP}$ & 0.2 & not rejected & 0.246 & not rejected \\
\hline \multirow{3}{*}{ S-Go/N-Me \% \#321 } & $\mathrm{RP}+\mathrm{Rg}$ & 0.2 & not rejected & 0.474 & not rejected \\
\hline & Rt & 0.2 & not rejected & 0.035 & rejected \\
\hline & $\mathrm{RP}$ & 0.2 & not rejected & 0.64 & not rejected \\
\hline \multirow{3}{*}{ H perp. MP } & $\mathrm{RP}+\mathrm{Rg}$ & 0.068 & not rejected & 0.066 & not rejected \\
\hline & Rt & 0.2 & not rejected & 0.863 & not rejected \\
\hline & $\mathrm{RP}$ & 0.2 & not rejected & 0.368 & not rejected \\
\hline \multirow{3}{*}{ H perp. C3-Me } & $\mathrm{RP}+\mathrm{Rg}$ & 0.2 & not rejected & 0.996 & not rejected \\
\hline & Rt & 0.2 & not rejected & 0.733 & not rejected \\
\hline & $\mathrm{RP}$ & 0.2 & not rejected & 0.354 & not rejected \\
\hline
\end{tabular}


Table 8: ANOVA tests for angular and linear measurements between sites of obstruction groups. $P$ value of significance: $P<0.05$.

\begin{tabular}{|c|c|c|c|c|c|}
\hline \multirow{2}{*}{$\begin{array}{c}\text { ANOVA/All groups/by } \\
\text { Localization } \\
\text { Variable }\end{array}$} & \multirow{2}{*}{$\begin{array}{l}\text { Levene's test for homogeneity of } \\
\text { variances } \\
\text { Sig. }\end{array}$} & \multicolumn{2}{|c|}{ Fisher's ANOVA Test } & \multirow{2}{*}{$\begin{array}{c}\text { Welch's robust Test } \\
\text { Sig. }\end{array}$} & \multirow{2}{*}{$\begin{array}{c}\text { Kruskal-Wallis Test } \\
\text { Sig. }\end{array}$} \\
\hline & & R-square & Sig. & & \\
\hline Y-axis to SN & 0.052 & 0.085 & 0.178 & 0.078 & 0.142 \\
\hline Gonial angle & 0.849 & 0.011 & 0.81 & 0.807 & 0.698 \\
\hline FMIA & 0.011 & 0.016 & 0.732 & 0.774 & 0.978 \\
\hline Soft palate angulation & 0.067 & 0.059 & 0.308 & 0.31 & 0.278 \\
\hline $\mathrm{C} 3-\mathrm{H}-\mathrm{Me}$ & 0.219 & 0.265 & 0.002 & 0.023 & 0.022 \\
\hline Go - Pg & 0.269 & 0.057 & 0.321 & 0.324 & 0.605 \\
\hline ANS-Me(ALFH)/N-Me(ATFH) & 0.268 & 0.026 & 0.596 & 0.532 & 0.657 \\
\hline PNS-U & 0.355 & 0.025 & 0.614 & 0.509 & 0.672 \\
\hline PNS-V & 0.754 & 0.254 & 0.003 & 0.018 & 0.017 \\
\hline $\mathrm{H}-\mathrm{TB}$ & 0.09 & 0.216 & 0.009 & 0.017 & 0.025 \\
\hline Sbtn-Phwn & 0 & 0.502 & 0 & 0 & 0 \\
\hline Soft palate thickness & 0.706 & 0.062 & 0.286 & 0.43 & 0.409 \\
\hline S-Go/N-Me \% \#321 & 0.657 & 0.058 & 0.313 & 0.336 & 0.299 \\
\hline H perp. MP & 0.356 & 0.322 & 0.001 & 0.009 & 0.007 \\
\hline $\mathrm{H}$ perp. C3-Me & 0.042 & 0.392 & 0 & 0.008 & 0.005 \\
\hline
\end{tabular}

Table 9: Multiple comparisons between significant measurements and sites of obstruction groups. $\mathrm{P}$ value of significance: $\mathrm{P}<0.05$.

\begin{tabular}{|c|c|c|c|c|c|}
\hline \multicolumn{6}{|c|}{ Multiple Comparisons } \\
\hline \multirow{2}{*}{ Variable } & \multirow{2}{*}{ Difference } & \multirow{2}{*}{ Mean Difference } & \multirow[b]{2}{*}{ Sig. } & \multicolumn{2}{|c|}{ 95\% Confidence Interval } \\
\hline & & & & Lower Bound & Upper Bound \\
\hline \multirow{3}{*}{ C3-H-Me } & $R P+R g-R t$ & -6.259 & 0.309 & -16.52 & 4.002 \\
\hline & $R P+R g-R P$ & 13.476 & 0.038 & 0.65 & 26.302 \\
\hline & $\mathrm{Rt}-\mathrm{RP}$ & 19.735 & 0.002 & 6.909 & 32.56 \\
\hline \multirow{3}{*}{ PNS-V } & $\mathrm{RP}+\mathrm{Rg}-\mathrm{Rt}$ & -2.776 & 0.554 & -9.258 & 3.705 \\
\hline & $R P+R g-R P$ & -12.032 & 0.002 & -20.134 & -3.929 \\
\hline & Rt - RP & -9.255 & 0.022 & -17.357 & -1.153 \\
\hline \multirow{3}{*}{ H-TB } & $\mathrm{RP}+\mathrm{Rg}-\mathrm{Rt}$ & -6.071 & 0.114 & -13.295 & 1.154 \\
\hline & $R P+R g-R P$ & -11.715 & 0.008 & -20.745 & -2.685 \\
\hline & Rt - RP & -5.644 & 0.292 & -14.674 & 3.386 \\
\hline \multirow{3}{*}{ Sbtn-Phwn } & $\mathrm{RP}+\mathrm{Rg}-\mathrm{Rt}$ & -3.2 & 0 & -4.481 & -1.919 \\
\hline & $R P+R g-R P$ & -0.69 & 0.551 & -2.291 & 0.911 \\
\hline & Rt - RP & 2.51 & 0.001 & 0.909 & 4.111 \\
\hline \multirow{3}{*}{ H perp. MP } & $\mathrm{RP}+\mathrm{Rg}-\mathrm{Rt}$ & -1.212 & 0.78 & -5.593 & 3.17 \\
\hline & $R P+R g-R P$ & -9.365 & 0 & -14.842 & -3.889 \\
\hline & Rt - RP & -8.154 & 0.002 & -13.63 & -2.677 \\
\hline \multirow{3}{*}{ H perp. C3-Me } & $\mathrm{RP}+\mathrm{Rg}-\mathrm{Rt}$ & 0.729 & 0.884 & -3.023 & 4.482 \\
\hline & $R P+R g-R P$ & -8.438 & 0 & -13.128 & -3.747 \\
\hline & $\mathrm{Rt}-\mathrm{RP}$ & -9.167 & 0 & -13.858 & -4.476 \\
\hline
\end{tabular}

mandible, a steep mandibular plane, and high upper and lower facial heights. In contrary to those findings, Kurt, et al. [11] found a hypo divergent tendency in the OSA group in comparison to controls.

\section{Sites of obstruction}

The comparison of angular and linear measurements using tests of normality for sites of obstruction groups are given in table 7 . The significant variables were then tested by: Fisher's ANOVA test; Welch's robust test; and Kruskal-Wallis test as shown in table 8. No statistically significant differences were observed in angular measurements between the three groups except for $\mathrm{C} 3-\mathrm{H}-\mathrm{Me}$. However linear measurements of soft palate thickness, the distance between the PNS and point V; and the distance between the hyoid and the following: tongue base, mandibular plane and C3-Me were found significant.

For those six variables that we found significant, we did not have equality in significances between the three obstruction sites groups, hence; those variables were compared two by two for further understanding of differences between the groups according to obstruction sites as shown in table 9 .

In our study, we have found that the Retrotonsillar group had longer faces in comparison to the Retropalatal group (Retrotonsillar group 
Table 10: Intra Class Correlation for reliability of measurements. P value of significance: $P<0.05$

\begin{tabular}{|c|c|c|c|c|c|}
\hline \multicolumn{6}{|c|}{ ANOVA } \\
\hline & & $\begin{array}{l}\text { Sum of } \\
\text { Squares }\end{array}$ & df & Sig. & ICC \\
\hline \multirow{3}{*}{ Gonial angle } & Between Groups & 725.983 & 19 & 0 & \multirow{3}{*}{0.999516} \\
\hline & Within Groups & 0.185 & 20 & & \\
\hline & Total & 726.168 & 39 & & \\
\hline \multirow{3}{*}{ H perp. MP } & Between groups & 1074.181 & 19 & 0 & \multirow{3}{*}{0.999794} \\
\hline & Within Groups & 0.116 & 20 & & \\
\hline & Total & 1074.297 & 39 & & \\
\hline
\end{tabular}

mean: $67.4 \mathrm{~mm} \pm 5.5$; Retropalatal group mean: $68.8 \mathrm{~mm} \pm 5.2)$ which was in accordance with the findings of Baik, et al. [7].

The findings of the present study revealed that the hyoid bone position was more inferiorly placed in the Retropalatal group (mean: $18.9 \pm 6.4$ ) in comparison to the Retropalatal plus Retroglossal group (mean: $10.5 \pm 3.4$ ), and Retrotonsillar group (mean: $9.8 \pm 4.4$ ), contrary to the findings of Baik, et al. [7] in which inferior position of the hyoid bone was most pronounced in the Retropalatal plus Retroglossal group but was also found in the Retropalatal and Retrotonsillar groups as well.

The Upper airway space assessment demonstrated that it was narrowest in the Retropalatal plus Retroglossal group (mean: $4.5 \mathrm{~mm}$ \pm 0.9 ) in comparison to Retropalatal group (mean: $5.2 \mathrm{~mm} \pm 0.6$ ), and Retrotonsillar group (mean: $7.7 \mathrm{~mm} \pm 2.2$ ) which was in accordance to the findings of Baik, et al. [7]

The findings of our research have shown that the tongue base measurement (PNS-V) was significantly lower in the Retropalatal group (mean: $88.5 \mathrm{~mm} \pm 9.3$ ) in comparison to the Retrotonsillar group (mean: $79.3 \mathrm{~mm} \pm 7.5$ ) and Retropalatal plus Retroglossal group (mean: $76.5 \mathrm{~mm} \pm 7.3$ ). The Retropalatal group showed thicker tongue mass (H-TB) than the Retropalatal plus Retroglossal group which was in contrary to the findings of Baik, et al. [2] in which the Retropalatal plus Retroglossal group showed thicker tongue mass in comparison to Retropalatal and Retrotonsillar groups.

\section{Measurements error}

The measurements error study was carried out by repeating the tracing and measurements of twenty randomly selected Cephalograms, again at an interval of two weeks. We used Intra Class correlation to test the Gonial angle measurement and $\mathrm{H}$ perpendicular $\mathrm{C} 3-\mathrm{Me}$ linear measurement that yielded ICC $=0.99$. Both of these measurements error were statistically insignificant as shown in table 10. Therefore, it can be concluded that no systematic error occurred for landmark identification or cephalometric measurements.

\section{Discussion}

The craniofacial anatomical risk factors, mechanism of upper airway compliance and muscle function play a role in OSA. However, many other etiological factors contribute to OSA including anatomic narrowing of the upper airway as a result of alterations in the craniofacial morphology or soft tissue enlargement, sleep posture, age, male gender, nasal obstruction, and adipose tissue in the pharynx have been suggested as etiologies of OSA by Battagel, et al. [17] and Tsai, et al. [10].
A Systematic Review by Guarda-Nardini, et al. [18] on the predictive value of anatomy based parameters in treatment for Obstructive Sleep Apnea with Intraoral Splint Devices have found that the mandibular plane angle and the distance between hyoid bone and mandibular plane have a predictive value for mandibular advancement devices (MAD) effectiveness in OSA patients. However, the relative weak inconsistent cephalometric data suggested that decisions based solely on these factors cannot be recommended and that other risk factors (e.g: age, sex, BMI) should be taken into consideration.

Because the structural relationship between the hard and soft tissues of the upper airway is confounded by obesity, which independently remains an important factor for increasing apneic activity, it is important to know which craniofacial parameters are risk factors for non-obese adults.

The relative position of the hyoid bone with both the mandible and vertebra; which is more accurate and easier than using the distance from the hyoid bone to the mandibular plane alone, was used in this study because the perpendicular distance from the hyoid bone to the mandibular plane may be influenced by the anteroposterior position of the hyoid bone: it increases when the hyoid bone is positioned posteriorly and decreases when the hyoid bone is positioned anteriorly as was shown by Tsai, et al. [13].

Concerning severity groups; Regression analysis showed that an inferiorly positioned hyoid bone is the most likely to be expected in patients with severe OSA and that the cephalometric variable $(\mathrm{H}$ perpendicular $\mathrm{C} 3-\mathrm{Me}$ ) is an effective cephalometric indicator of OSA in Non Obese Males.

As for Sites of Obstruction; the Retropalatal plus Retroglossal and Retrotonsillar groups were more prevalent in our OSA sample than Retropalatal obstruction which was not in accordance to the findings of Baik, et al. [7] in which the Retropalatal obstructive type was the most common of all of the obstructive types of OSA.

The results of our study suggest that the Retropalatal and Retroglossal obstructions have to be examined carefully when a patient with OSA presents with a certain level of skeletal Class II tendency. To relieve obstruction at the Retroglossal site, site-specific surgery (reduction of the base of the tongue and other procedures) may be effective. Furthermore, it is hypothesized that mandibular advancement therapy such as therapy with an oral appliance or orthognathic surgery would be effective as advocated by Fujita, et al. [19]. Airway obstruction in patients with OSA may be caused by a lack of airway-dilating muscle activity and tissue compliance against the intraluminal negative pressure and gravity on inspiration. Among the airway-dilating muscles, the geniohyoid, genioglossus, and mylohyoid muscles are the main large muscles. They are attached to the body and symphysis of the mandible, tongue, and hyoid bone. Thus, retrognathia or micrognathia results in posterior displacement of the tongue, an inferior position of the hyoid bone, and narrowing of the airway, which can predispose to the obstruction of the upper airway.

\section{Conclusion}

The following conclusions could be drawn:

- The distance from a line from the C3-Me perpendicular to the hyoid bone on lateral cephalometric radiographs may be used as a cephalometric indicator in severe OSA patients and aid in better understanding of the obstruction site mechanism in non-obese Lebanese men. Based on the result of the regression analysis, inferiorly positioned hyoid bone is most likely to be expected in patients with severe OSA. 
- $\quad$ The Jarabak facial ratio showed a hyper divergent facial type and increase in the posterior facial height for the two severity groups in comparison with controls.

- The Retrotonsillar group had longer faces in comparison to the Retropalatal group.

- $\quad$ Palate length and thickness were significantly higher with severity of the OSA which was also revealed by our results in the mild to moderate and severe group in comparison to control group

- Retrotonsillar and Retropalatal plus Retroglossal obstruction sites were more prevalent in our sample.

- The two OSA severity groups tongue base was in a more inferior position in relation to control subjects.

\section{Recommendations}

Further studies to investigate the effect of the sites of obstruction in OSA on dentofacial morphology is needed with larger number of subjects and using better method design in the localization of obstruction sites.

We suggest that the Retropalatal and Retroglossal obstructions have to be examined carefully when a patient with OSA shows a certain level of skeletal Class II tendency.

\section{Limitations}

In regard to the sites of obstruction classification from the cephalometric radiograph; more reliable and powerful methods using MRI or supine Cephalometric imaging could have been used to better determine the site of obstruction since the narrowest portion of the airway on a $2 \mathrm{D}$ film in an awake upright subject may not be the same as the actual position of obstruction in a sleeping supine sleep apneic patient.

Another limitation is in the Retrotonsillar group site of obstruction, we did not measure the Palatine Tonsil size rather than the constriction in the area behind the tonsil so that may have not well determined the Tonsillar hypertrophy precisely.

\section{References}

1. Koubayashi S, Nishida A, Nakagawa M, Shoda, Wada K, et al. (1989) Dentofacial morphology of obstructive sleep apnea syndrome patients. Nihon Kyosei Shika Gakkai Zasshi 48: 391-403.

2. Hou H, Sam K, Hagg U, Rabie AB, Bendeus M, et al. (2006) Long-term dentofacial changes in Chinese obstructive sleep apnea patients after treatment with a mandibular advancement device. Angle Orthod 76: 432-440.

3. Bacon WH, Turiot JC, Krieger J, Stierle JL (1989) Cephalometric evaluation of pharyngeal obstructive factors in patients with sleep apnea syndrome. Angle Orthod 60: 115-122.

4. Kubota Y, Nakayama H, Takada T, Matsuyama N, Sakai K, et al. (2005) Facial axis angle as a risk factor for obstructive sleep apnea. Intern Med 44: 805-810.
5. Lowe AA, Santamaria JD, Fleetham JA, Price C (1986) Facial morphology and obstructive sleep apnea. Am J Orthod Dentofacial Orthop 90: 484-491.

6. Lowe A, Fleetham J, Adachi S, Ryan CF (1995) Cephalometric and computed tomographic predictors of obstructive sleep apnea severity. Am J Orthod Dentofac Orthop 107: 589-595.

7. Baik U, Masaaki S, Katsuhisa L, Sugawara J, Mitani H. (2002) Relationship Between Cephalometric Characteristics and Obstructive Sites in Obstructive Sleep Apnea Syndrome. Angle Orthod 72: 124-134.

8. Fukuda N, Abe T, Katagiri M, Yokoba M, Okamoto M, et al. (1998) Effect of uvulopalatopharyngoplasty on patients with obstructive sleep apnea-the severity of preoperative tonsillar hypertrophy. Nihon Kokyuki Gakkai Zasshi 36: 34-40.

9. Sakakibara H, Tong M, Matsushita K, Hirata M, Konishi Y, et al. (1999) Cephalometric abnormalities in non-obese and obese patients with obstructive sleep apnea. Eur Respir J 13: 403-410.

10. Tsai H, Ho C, Lee P, Tan CT (2007) Cephalometric analysis of nonobese snorers either with or without obstructive sleep apnea syndrome. Angle Orthod 77: 1054-1061.

11. Kurt G, Sisman C, Akin E, Akcam T (2011) Cephalometric Comparison of Pharyngeal Airway in Snoring and Non-Snoring Patients. Eur J Dent 5: 84-88.

12. Jamieson A, Guilleminault C, Partinen M, Quera-Salva MA (1986) Obstructive sleep apneic patients have craniomandibular abnormalities. Sleep 9: 469-477.

13. Tsai H, Ho CY, Lee PL, Tan CT (2009). Sex differences in anthropometric and cephalometric characteristics in the severity of obstructive sleep apnea syndrome. Am J Orthod Dentofacial Orthop 135: 155164.

14. Lyberg T, Krogstad O, Djupesland G (1989) Cephalometric analysis in patients with obstructive sleep apnoea syndrome: II. Soft tissue morphology. J Laryngol Otol 103: 293-297.

15. Hou H, Hagg U, Sam K, Rabie AB, Wong RW, et al. (2005) Dentofacial Characteristics of Chinese Obstructive Sleep Apnea Patients in Relation to Obesity and Severity. Angle Orthod 76: 962-969.

16. Tangugsorn V, Skatvedt O, Krogstad O, Lyberg T (1995) Obstructive sleep apnoea: a cephalometric study. Part I. Cervico-craniofacial skeletal morphology. Eur J Orthod 17: 45-56.

17. Battagel JM, L'Estrange PR (1996) The cephalometric morphology of patients with obstructive sleep apnoea (OSA). Eur J Orthod 18: 557-569.

18. Guarda-Nardini L, Manfredini D, Mion M, Heir G, Marchese-Ragona R (2015) Anatomically Based Outcome Predictors of Treatment for Obstructive Sleep Apnea with Intraoral Splint Devices: A Systematic Review of Cephalometric Studies. J Clin Sleep Med 11: 1327-1334.

19. Fujita S, Conway W, Zorick F, Roth T (1981) Surgical correction of anatomic abnormalities in obstructive sleep apnea syndrome: uvuolopalatopharyngoplasty. Otolaryngol Head Neck Surg 89: 923934 